\title{
Catchment scale assessment of risk posed by traffic generated heavy metals and polycyclic aromatic hydrocarbons
}

\author{
Yukun Ma ${ }^{\mathrm{a}, \mathrm{b}}$, James McGree ${ }^{\mathrm{b}}$, An Liu ${ }^{\mathrm{b}, \mathrm{c}, *}$, Kaveh Deilami ${ }^{\mathrm{b}}$, Prasanna Egodawatta ${ }^{\mathrm{b}}$, \\ Ashantha Goonetilleke ${ }^{\mathrm{b}}$ \\ ${ }^{a}$ State Key Laboratory of Urban and Regional Ecology, Research Center for Eco-Environmental Sciences, Chinese Academy of Sciences, 18 Shuangqing Road, Beijing \\ 100085, China \\ b Science and Engineering Faculty, Queensland University of Technology (QUT), GPO Box 2434, Brisbane, 4001 Queensland, Australia \\ ${ }^{c}$ College of Chemistry and Environmental Engineering, Shenzhen University, 518060 Shenzhen, China
}

\section{A R T I C L E I N F O}

\section{Keywords:}

Heavy metals

Polycyclic aromatic hydrocarbons

Risk assessment

Stormwater quality

Stormwater pollutant processes

\begin{abstract}
A B S T R A C T
Heavy metals (HMs) and polycyclic aromatic hydrocarbons (PAHs) are among the most toxic chemical pollutants present in urban stormwater. Consequently, urban stormwater reuse is constrained due to the human health risk posed by these pollutants. This study developed a scientifically robust approach to assess the risk to human health posed by HMs and PAHs in urban stormwater in order to enhance its reuse. Accordingly, an innovative methodology was created consisting of four stages: quantification of traffic and land use parameters; estimation of pollutant concentrations for model development; risk assessment, and risk map presentation. This methodology will contribute to catchment scale assessment of the risk associated with urban stormwater and for risk mitigation. The risk map developed provides a simple and efficient approach to identify the critical areas within a large catchment. The study also found that heavy molecular weight PAHs (PAHs with 5-6 benzene rings) in urban stormwater pose higher risk to human health compared to light molecular PAHs (PAHs with 2-4 benzene rings). These outcomes will facilitate the development of practical approaches for applying appropriate mitigation measures for the safe management of urban stormwater pollution and for the identification of enhanced reuse opportunities.
\end{abstract}

\section{Introduction}

From recent years, urban stormwater is being increasingly recognised as an alternative water resource which can be used for recreational and potable purposes to meet the ever increasing urban water demand (Liu et al., 2015). However, past research studies have noted that the concentrations of heavy metals (HMs) and polycyclic aromatic hydrocarbons (PAHs) in stormwater, which are primarily contributed by traffic activities can exceed the corresponding guideline thresholds specified for recreational and potable water, thus posing a potential risk to human health through reuse (Birch et al., 2004; Herngren, 2005; Wang et al., 2013). Consequently, an in-depth understanding of human health risk posed by HMs and PAHs in urban stormwater is critical for its reuse.

In order to effectively manage the risk associated with stormwater reuse, efficient and targeted management strategies need to be undertaken. This can be implemented by identifying the highly polluted areas and the toxic chemical pollutants in urban stormwater that pose a risk to human health. Ma et al. (2016) developed a quantitative procedure to estimate the risk to human health posed by HMs in urban stormwater generated from individual study sites based on traffic volume and percentages of different land uses. However, the management of the potential risk from urban stormwater generated from a catchment instead of individual sites has more practical value for the purpose of stormwater reuse. In terms of urban stormwater management in relation to a catchment, prioritising of critical areas which are relatively highly polluted by toxic pollutants such as HMs and PAHs and specific pollutant species provides significant benefits. Consequently, the development of a reliable and accurate approach to quantitatively estimate the human health risk associated with urban stormwater from a catchment is essential for urban stormwater management.

In addition to the identification of relatively highly polluted areas, identification of the most toxic chemical pollutants in urban stormwater is also essential. For example, some HMs can be toxic to human health even at low concentrations while other species though being present in high concentrations, pose a relatively lower risk (Zheng et al., 2007;

\footnotetext{
* Corresponding author

E-mail address: liuan@szu.edu.cn (A. Liu).
} 
Khillare et al., 2014). However, current stormwater treatment methods do not consider the risk posed by the specific pollutants in urban stormwater. As a consequence, stormwater management techniques are limited in their ability to target the removal of the most toxic HM and PAH species in urban stormwater.

Accordingly, the main objectives of this research study were: (1) to create a mathematical approach to quantitatively assess the risk from urban stormwater generated from a catchment area; (2) to develop a reliable and accurate approach to identify the highly polluted areas based on risk assessment of HMs and PAHs present in urban stormwater generated at catchment scale in order to underpin the effective management of the identified risk. It is important to note that this study focused on human health risk associated with traffic generated pollutants in stormwater.

\section{Materials and methods}

\subsection{Study sites}

Twenty road sites were selected from the Gold Coast, Australia. As traffic volume and land use were commonly viewed as the two most influential parameters for HM and PAH generation and re-distribution on urban roads (Gunawardena et al., 2014b, 2014a; Ma et al., 2017a), the road sites were selected from five different suburbs with different land uses and from each suburb, four sites with different daily traffic volumes (DTV) [vehicles per day] were identified. This ensured a representative cross-selection in relation to HMs and PAHs distribution in terms of concentrations and species. The five suburbs and their land use types are shown in Fig. 1.

\subsection{Build-up sample collection}

Build-up sample collection was conducted on the road surfaces at the selected study sites. Although wash-off also influences the quality of stormwater, a single stormwater runoff event can remove only a fraction of the build-up pollutants (Egodawatta et al., 2007). Hence, in order to estimate the maximum possible risk posed by the pollutants in stormwater, only build-up samples were collected. According to previous studies, stormwater runoff quality is primarily influenced by the build-up of pollutants on both, road and roof surfaces (Egodawatta et al., 2009; Gunawardena et al., 2014b). The procedure outlined by Egodawatta et al. (2009) can be used to estimate the build-up load of solids deposited on roof surfaces based on the build-up load of solids on the road surfaces in the same study area.

Considering the variability in the adsorption of HMs and PAHs to solids, build-up samples were collected twice at the same study site and the average build-up load of pollutants was used for the analysis. The two sample collections were undertaken after seven to nine dry days. This approach was adopted due to the fact that the build-up load of solids on roads can approximate to a relatively constant value after this time period (Egodawatta and Goonetilleke, 2006). Accordingly, a total of 40 build-up samples were collected. The sampling procedure was conducted within a small plot at each site (width: one meter $\times$ length equal to the distance from the kerb to the middle) due to the nonhomogeneous particle size distribution across the road surface (Novotny et al., 1985). Dry and wet vacuuming procedure used by Gunawardana et al. (2012) was adopted for collecting the build-up samples. The efficiency of the equipment for sampling was ascertained to be over $95 \%$, which was considered as acceptable.

\subsection{Laboratory analysis}

The build-up load of nine HMs and 15 PAHs (Table 1), which are the most common toxic chemical pollutants present in urban stormwater were analysed (Chiew et al., 1997). Although there are 16 PAH species identified by the US EPA as priority pollutants, this study tested only 15 of them as Benzo[ $k]$ flouranthene was not present in the standards used. HMs were extracted using nitric acid digestion according to Method 3030E (APHA, 2004), which has been adopted by numerous past research studies (Herngren et al., 2005; Gunawardana et al., 2011). The concentration of HMs in the extract was tested based on the procedure specified in US EPA Method 200.8 (US EPA, 1994) using an Agilent 8800 Triple Quadrupole Inductively Coupled Plasma Mass Spectrometer (ICP-MS). In terms of PAHs, the aqueous and particulate fractions were separated and extracted according to US EPA method 610 (US EPA, 1984) and US EPA method 3545 (US EPA, 1996), respectively. The extracts were tested for the 15 PAHs using a Shimadzu Gas Chromatograph Mass Spectrometer (GC-MS) TQ8030. The load of HMs and PAHs in the total build-up solids from the two sampling episodes is detailed in Table S1 and S2 in the Supplementary Information. As part of quality assurance and quality control, laboratory fortified blanks were prepared by adding a known amount of calibration standard to the laboratory blanks in order to assess the recovery of the digestion and test. The recovery of HMs and PAHs was always within $85-105 \%$ and 75-105\%, respectively, which was confirmed by previous research studies as meeting the requirement of the standard methods adopted (Gunawardana et al., 2014; Ma et al., 2017b). Additionally, field reagent blanks, laboratory regent blanks, calibration blanks, calibration standards and internal standards were also used during laboratory analysis according to the quality control procedures described in US EPA Method 200.8 (US EPA, 1994).

\section{Research design approach}

The approach adopted for assessing the risk posed by HMs and PAHs in stormwater generated from a selected catchment is illustrated in Fig. 2. The catchment was initially divided into a number of grid cells and the risk associated with stormwater from each grid cell was assessed. Risk assessment was undertaken in four stages: (1) identification of traffic and land use parameters in each grid cell using ArcMap software (ESRI, 2016); (2) development of a model which captures the relationship between pollutant concentration and traffic and land use; (3) assessment of the risk from stormwater in each grid cell; (4) presentation of the predicted risk as a map representation.

\subsection{Quantification of traffic and land use parameters}

Quantification of parameters was undertaken using $1 \mathrm{~km} \times 1 \mathrm{~km}$ grid cells and considering each grid cell as a unit entity for assessing risk. Accordingly, the selected study catchment was demarcated into 96 grid cells ( 6 rows $\times 16$ columns) using ArcMap software. It is important to note that the primary focus of this study was to demonstrate the development of this innovative approach for risk assessment. The grid cell size can be varied to suit the given catchment and its spatial characteristics. The daily traffic volume of a road near to the centroid of a grid cell was identified by ArcMap to represent traffic volume within the grid cell. If there was no road near to the centroid of the grid cell (e.g. forest or waterbody), the traffic volume for the grid cell was taken as zero since the contribution to risk from traffic at this grid cell would be minimal. It is important to note that this study was primarily based on HMs and PAHs generated by traffic and land use activities. The HMs and PAHs tested were those commonly present in the urban environment and has been previously identified as primarily traffic generated (Gunawardena et al., 2012; Mummullage et al., 2016). Furthermore, the study sites selected does not contain any industry which could generate these pollutant types. The land use parameter was determined as the percentage of commercial, industrial and/or residential land use area (C, I and/or R) within each grid cell using ArcMap. The traffic and land use data were provided by Gold Coast City Council. 

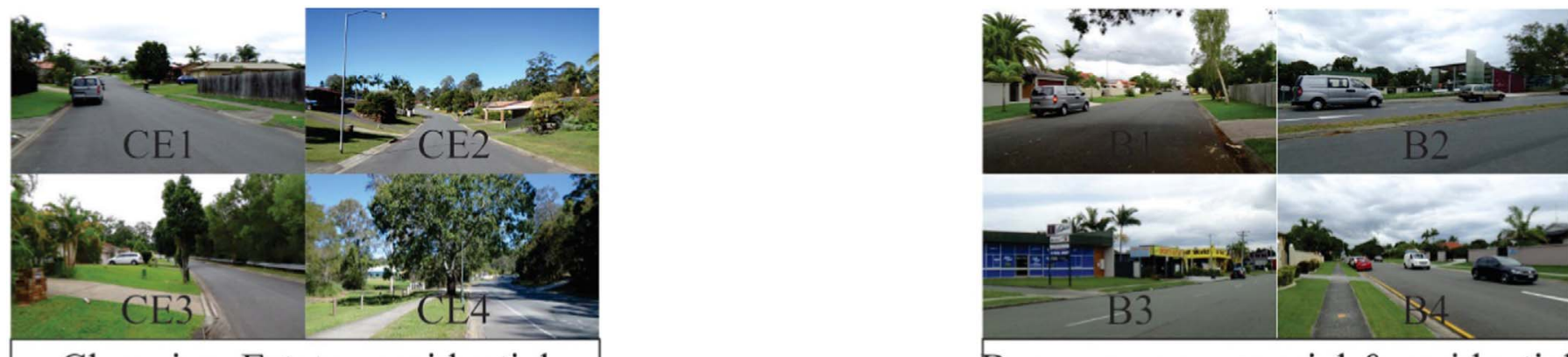

\section{Clearview Estate - residentia}
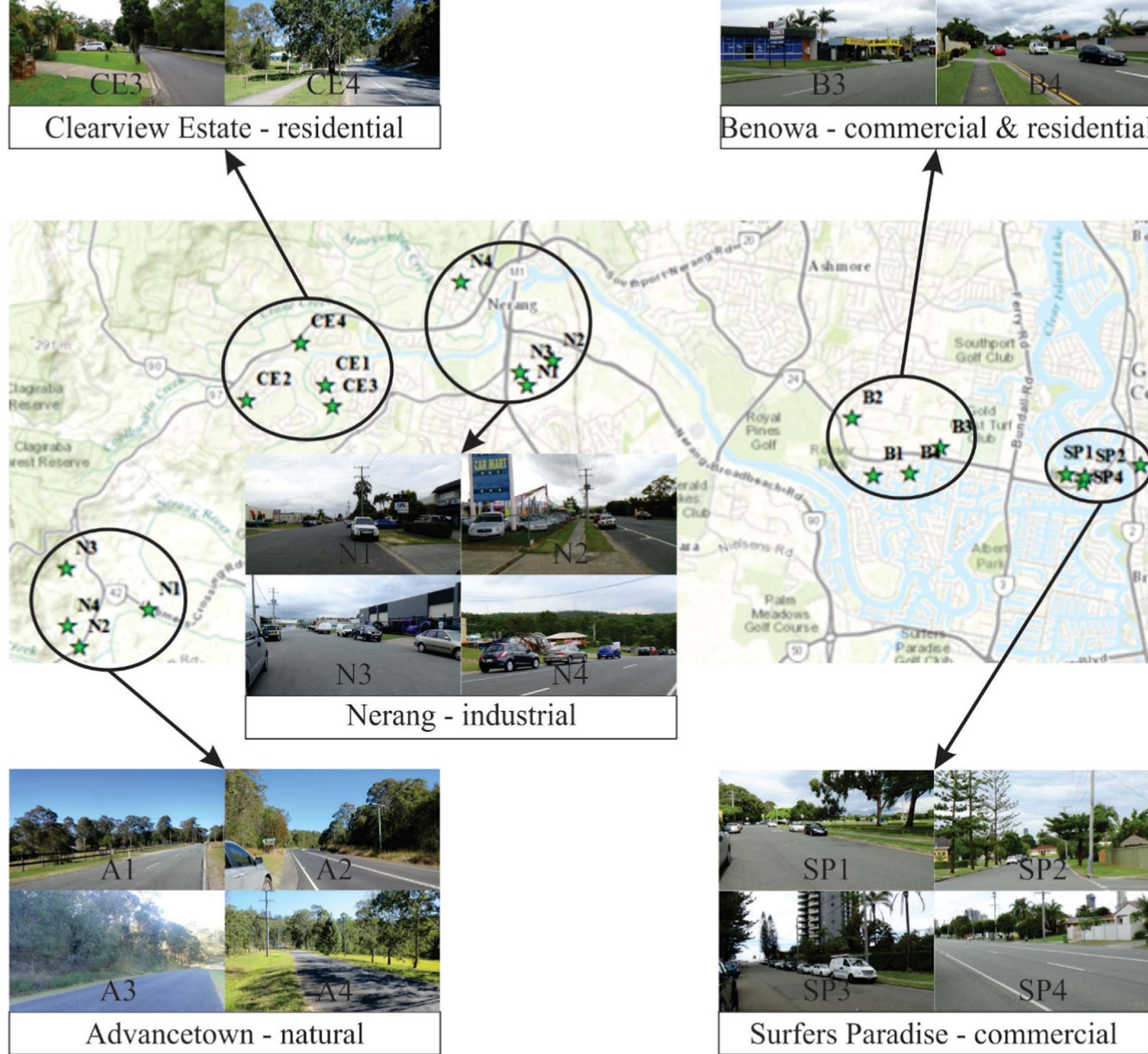

Benowa - commercial \& residential
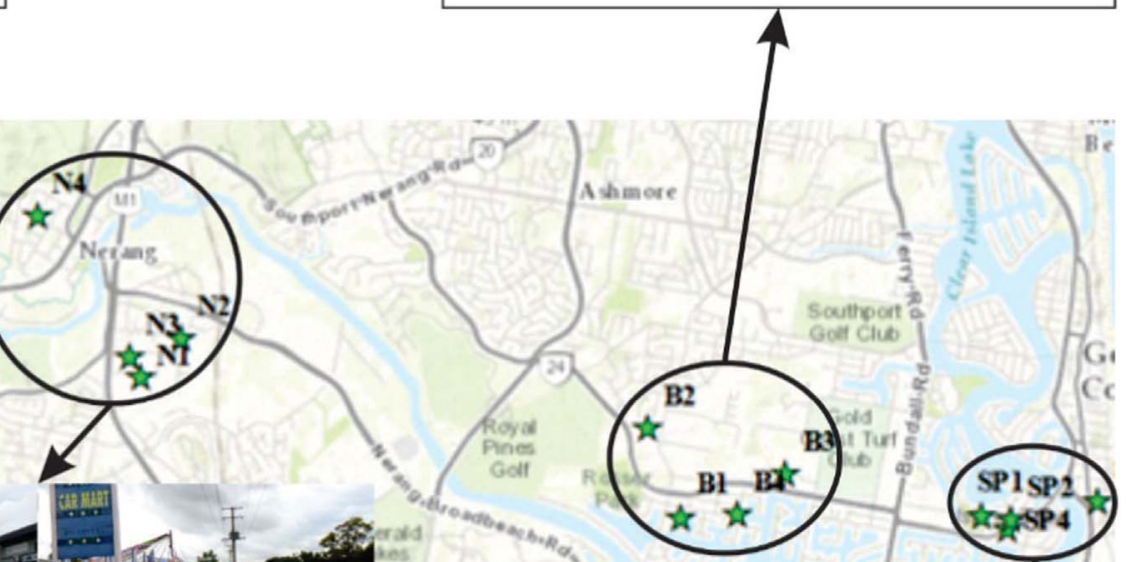
Table 1

Tested HMs and PAHs in the build-up samples.

\begin{tabular}{|c|c|c|c|c|}
\hline HMs & Abbr. & PAHs & Abbr. & $\begin{array}{l}\text { Toxic equivalent factors } \\
\text { (TEF) }\end{array}$ \\
\hline Aluminium & $\mathrm{Al}$ & Acenaphthene & $\mathrm{ACY}$ & 0.001 \\
\hline Cadmium & $\mathrm{Cd}$ & Acenaphthylene & ACE & 0.001 \\
\hline Chromium & $\mathrm{Cr}$ & Anthracene & ANT & 0.01 \\
\hline Copper & $\mathrm{Cu}$ & Benzo $[a]$ anthracene & $\mathrm{B}[a] \mathrm{A}$ & 0.1 \\
\hline Iron & $\mathrm{Fe}$ & Benzo $[a]$ pyrene & $\mathrm{B}[a] \mathrm{P}$ & 1 \\
\hline Lead & $\mathrm{Pb}$ & Benzo $[b]$ fluoranthene & $\mathrm{B}[b] \mathrm{F}$ & 0.1 \\
\hline Manganese & Mn & Benzo[ghi]perylene & $\mathrm{B}[g] \mathrm{P}$ & 0.01 \\
\hline Nickel & $\mathrm{Ni}$ & Chrysene & CHR & 0.01 \\
\hline \multirow[t]{7}{*}{ Zinc } & $\mathrm{Zn}$ & $\begin{array}{l}\text { Dibenzo }[a, h] \\
\text { anthracene }\end{array}$ & $\mathrm{D}[a] \mathrm{A}$ & 5 \\
\hline & & Fluoranthene & FLA & 0.001 \\
\hline & & Fluorene & FLU & 0.001 \\
\hline & & $\begin{array}{l}\text { Indeno[1,2,3-cd] } \\
\text { pyrene }\end{array}$ & IND & 0.1 \\
\hline & & Naphthalene & NAP & 0.001 \\
\hline & & Phenanthrene & PHE & 0.001 \\
\hline & & Pyrene & PYR & 0.001 \\
\hline
\end{tabular}

Note: The toxic equivalent factors (TEF) were derived from Nisbet and LaGoy (Nisbet and LaGoy, 1992).

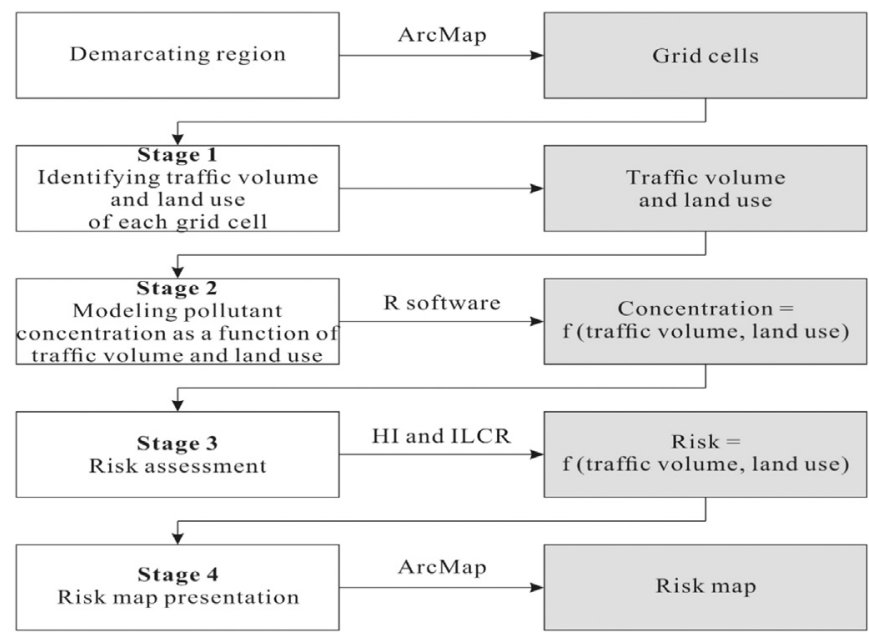

Fig. 2. Research design for assessing risk from a catchment.

variance of the logarithmic concentration data can be described as a function of distance.

Accordingly, the initial geospatial modelling was undertaken using geoR package in R software. The concentration of HMs and PAHs was modelled as a function of daily traffic volume and different land use area fraction via a geostatistical linear model. Any trend in residual variability was excluded and the distribution of the predicted concentration data against the observed data was checked along the line $\mathrm{y}=\mathrm{x}$. Detailed information on the modelling procedure can be found in Ma et al. (2016). However, the modelling procedure adopted in Ma et al. (2016) is for estimating the risk at specific locations, while the proposed approach in this paper provides further steps for interpolating the risk across a large region or catchment. The traffic and land use parameters at the study sites are presented in Table S3 in the Supplementary Information. Spatial variability in data can be assessed via a variogram which gives the variability in the response based on the distance from a site (Cressie, 2015). Typically, a variogram will increase with distance until sites are far enough apart such that they can be considered independent (from each other). Such a variogram was plotted for log concentration data for this study, and can be seen in Fig. 3 for Al (for example). As evident, there is little difference in the variability of the data across distance, suggesting that there is no spatial variability in the data. This was confirmed by Akaike's Information

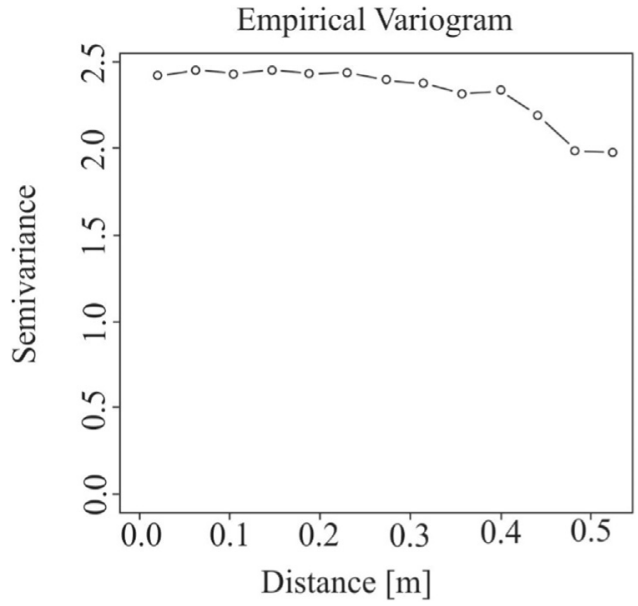

Fig. 3. Variogram for the original data set.

Criterion (AIC) which can be used for model selection and the model that gives the smallest AIC values is preferred (Bozdogan, 1987). The model without spatial variability gave smaller AIC values compared to the geostatistical models. This further confirmed that the geostatistical model was not suitable. Similar results were observed for all HMs and PAHs.

Given this finding, interpolation procedures such as those based on kriging methods were not employed to predict concentration of pollutants at sites not sampled. Instead, sites not sampled were treated as independent and predictions were based on a linear regression model. Accordingly, the concentration of pollutants was modelled as a function in the form of Eq. (1). Goodness-of-fit of the model was assessed by inspecting the residuals to ensure the validity of statistical assumptions made. There were occasions where curvature was apparent in the residuals, and this was accounted for via an appropriate quadratic term.

$\log$ Concentration $=\beta_{0}+\beta_{1} \times \log D T V+\beta_{2} \times C+\beta_{3} \times I+\beta_{4} \times R$

Where: $\beta_{0}, \beta_{1}, \beta_{2}, \beta_{3}$ and $\beta_{4}$ - coefficients;

$\log D T V$ - logarithmic form of daily traffic volume;

$C, I$ and $R$ - percentage of commercial, industrial and residential land use area within the grid cell.

To investigate the ability of the developed model for accurately predicting 'new' data, the leave-one-out cross-validation approach was adopted (Wold, 1978). Fig. 4 shows a comparison of predicted concentration of $\mathrm{Al}$ (vertical line) when this site was omitted from the data set, with the observed concentrations of $\mathrm{Al}$ (density plot) at an omitted study site. It is evident that the predicted concentration value lies in the area of high density of the observed data and this was also checked for

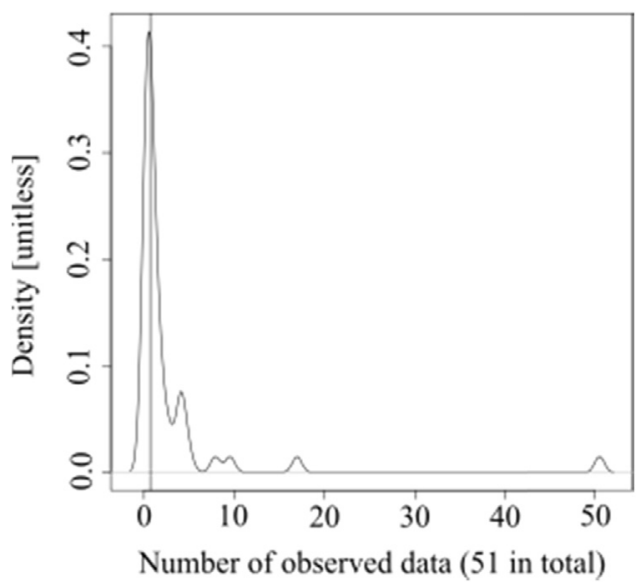

Fig. 4. Comparison of observed $\mathrm{Al}$ concentration at SP1 (density plot) with predicted $\mathrm{Al}$ concentration (vertical line) at SP1. 
Table 2

Empirical for estimating the concentration of HMs and PAHs in stormwater.

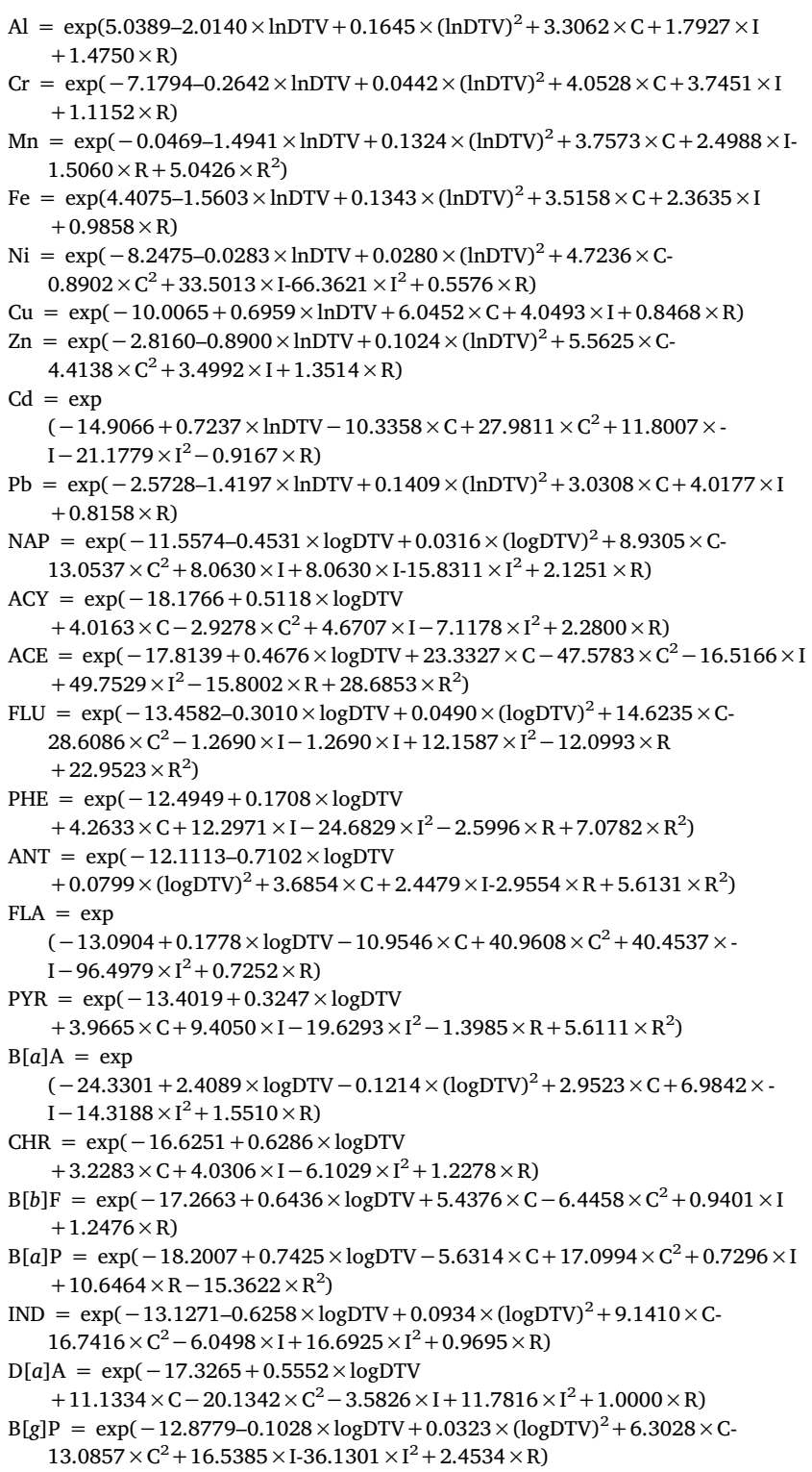

Note: DTV - daily traffic volume [average vehicles per day].

$\mathrm{C}$, I and $\mathrm{R}$ - percentage of commercial, industrial and residential land use areas.

all the study sites. Hence, the model was considered valid for estimating $\mathrm{Al}$ at locations not sampled. Similar results were observed for all HMs and PAHs.

The empirical models for estimating the concentration of HMs and PAHs in urban stormwater is shown in Table 2. The estimates, standard errors and $\mathrm{p}$ values derived from the modelling are provided in Table S4 in the Supplementary Information.

\subsection{Risk assessment}

The risk of HMs in urban stormwater was assessed via the hazard index (HI) and hazard quotient (HQ) approach. Hazard quotient is calculated by dividing the intake of a HM with its corresponding US EPA reference dose (IRIS, 2015). Hazard index is the sum of hazard quotient to represent the combined toxic effects posed by multiple HMs. According to US EPA (1989), HI $>1$ means that HMs can pose risk to human health while $\mathrm{HI}<1$ indicates that HMs are not toxic to human health.
The procedure for assessing the risk posed by PAHs in urban stormwater is discussed below. The risk from PAHs was assessed based on the toxic equivalent factor (TEF) approach. This approach is used widely for estimating the risks posted by PAHs (Chen and Liao, 2006; Jiang et al., 2014). The TEF approach assesses the combined concentration of all PAHs instead of individual concentration as the PAHs commonly exist as a group. This approach uses benzo $[a]$ pyrene $(\mathrm{B}[a] \mathrm{P})$ as the reference compound and assigns TEF values (see Table 1) for other PAHs (Nisbet and LaGoy, 1992). The combined concentration of the PAH mixture was assessed as benzo $[a]$ pyrene equivalent concentration (B $\left.[a] \mathrm{P}_{\mathrm{eq}}\right)$ and calculated using Eq. (2) (Jyethi et al., 2014).

$B[a] P_{e q}=\sum_{i=1}^{n} C_{i} \times T E F_{i}+\mathrm{X}$

Where: $C_{i}$ - the concentration of the $\mathrm{i}^{\text {th }} \mathrm{PAH}$ detected in the mixture;

$T E F_{i}$ - the TEF value of the $\mathrm{i}^{\text {th }} \mathrm{PAH}$ detected in the mixture;

$n$ - the number of PAHs detected in the mixture; and

$\mathrm{X}$ - the concentration of $\mathrm{B}[a] \mathrm{P}$ in the mixture.

According to US EPA (1989), people can be exposed to HMs and PAHs in surface water through three exposure pathways: ingestion due to drinking (WI); accidental ingestion while swimming (SI); and dermal contact (DC). Urban stormwater runoff can be considered as a component of surface water. Therefore, the three exposure pathways identified for surface water were considered relevant for exposure assessment. The intake of PAHs in stormwater through these three pathways can be calculated according to Eqs. (3)-(5) (Ma et al., 2016).

$$
\begin{aligned}
& \text { Intake }_{W I}=\frac{C \times I R_{W} \times E F \times E D}{B W \times 365 \text { days } / \text { year } \times A T} \\
& \text { Intake }_{S I}=\frac{C \times C R \times E T_{D} \times E F_{D} \times E D}{B W \times 365 \text { days } / \text { year } \times A T} \\
& \text { Intake }_{D C}=\frac{C \times S A \times P C \times E T_{D} \times E F_{D} \times E D \times C F}{B W \times 365 \text { days } / \text { year } \times A T}
\end{aligned}
$$

Where: Intake ${ }_{W I}$, Intake $e_{S I}$, Intake $e_{D C}$ - daily intake of PAHs in stormwater through the

three exposure pathways;

$C$ - is the concentration of PAH in stormwater $(\mathrm{mg} / \mathrm{L})$;

$I R_{W}$ - water ingestion rate (2 L/day);

$C R$ - contact rate $(0.05 \mathrm{~L} /$ hour $)$;

$E T_{D}$ - exposure time while swimming $(2.6 \mathrm{~h} / \mathrm{event})$

$E F_{D}$ - exposure frequency for swimming (7 events/year);

$S A$ - skin surface area available for contact $\left(18,000 \mathrm{~cm}^{2}\right)$;

$P C$ - chemical-specific dermal permeability constant $(0.7 \mathrm{~cm} /$ hour $)$;

$C F$ - volumetric conversion for water $\left(1 \mathrm{~L} / 1000 \mathrm{~cm}^{3}\right)$;

$E F$ - exposure frequency (365 days/year);

$E D$ - exposure duration (30 years);

$C F$ - body weight of an adult $(70 \mathrm{~kg})$;

$A T$ - averaging time during exposure (70 years). The values of the parameters in Eqs. (3)-(5) were adapted from US EPA (1989).

As the carcinogenic effect of PAHs is of most concern in risk assessment, the cancer risk posed by PAHs in urban stormwater is assessed as incremental lifetime cancer risk (ILCR) using Eqs. (6)-(8) (US EPA, 2005). If ILCR is $>10^{-6}$, there is no cancer risk from PAHs in urban stormwater. If ILCR is between $10^{-6}$ and $10^{-4}$, there might be cancer risk within acceptable range. If ILCR is $>10^{-4}$, the PAHs pose cancer risk (US EPA, 1989). The cancer slope factor (CSF) is used in risk assessment to define the maximum threshold of the probability of a cancer response per unit intake of benzo[ $[a]$ pyrene by an adult over the lifetime (US EPA, 1989).

$$
\begin{aligned}
& I L C R_{\text {oral }}=\left(\text { Intake }_{W I}+\text { Intake }_{S I}\right) \times C S F_{\text {oral }} \\
& I L C R_{\text {dermal }}=\text { Intake }_{D C} \times C S F_{\text {dermal }} \\
& I L C R=I L C R_{\text {oral }}+I L C R_{\text {dermal }}
\end{aligned}
$$




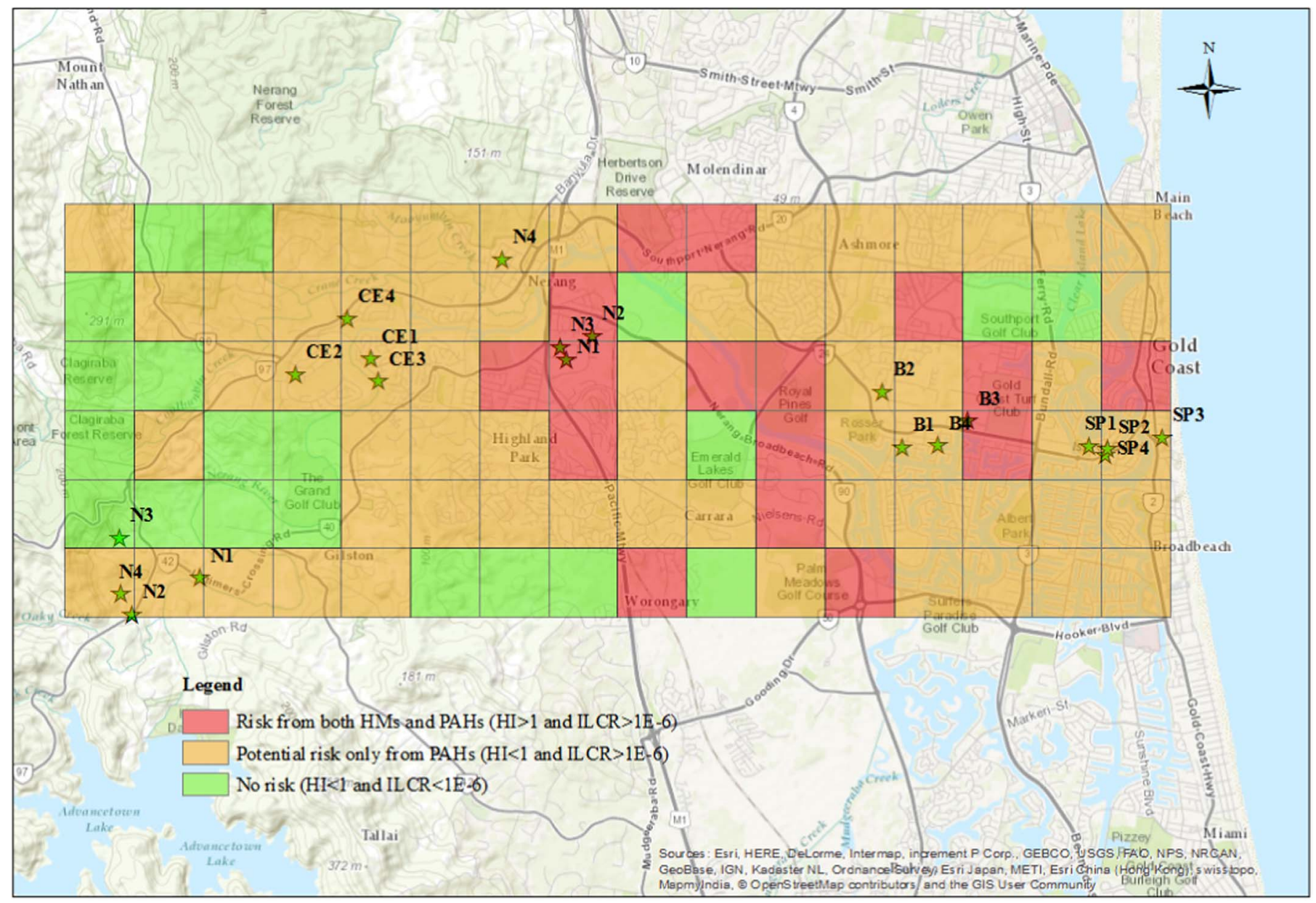

Fig. 5. Risk map for HMs and PAHs load in stormwater (Note: the condition of potential risk only from HMs load with HI $>1$ or PAHs load with ILCR $<10^{-4}$ was not found).

Table 3

Contribution of the risk from single PAH in stormwater.

\begin{tabular}{lll}
\hline PAHs & Contribution & Number of benzene rings \\
\hline D $[a] \mathrm{A}$ & $60.70 \%$ & 5 \\
B $[a] \mathrm{P}$ & $30.76 \%$ & 5 \\
$\mathrm{IND}$ & $2.28 \%$ & 6 \\
$\mathrm{~B}[b] \mathrm{F}$ & $2.20 \%$ & 5 \\
$\mathrm{~B}[a] \mathrm{A}$ & $1.15 \%$ & 4 \\
$\mathrm{~B}[\mathrm{~g}] \mathrm{P}$ & $0.94 \%$ & 6 \\
FLA & $0.92 \%$ & 4 \\
CHR & $0.38 \%$ & 4 \\
FLU & $0.16 \%$ & 3 \\
ANT & $0.14 \%$ & 3 \\
PYR & $0.14 \%$ & 4 \\
PHE & $0.11 \%$ & 3 \\
ACE & $0.08 \%$ & 3 \\
NAP & $0.04 \%$ & 2 \\
ACY & $0.005 \%$ & 3 \\
\hline
\end{tabular}

Where: $I L C R_{\text {oral }}$ and $I L C R_{\text {dermal }}$ - cancer risk probability through oral ingestion and

dermal contact;

$C S F_{\text {oral }}$ and $C S F_{\text {dermal }}$ - cancer slope factor of benzo $[a]$ pyrene through oral ingestion and dermal contact $\left((\mathrm{mg} / \mathrm{kg} \cdot \mathrm{day})^{-1}\right)$.

Based on equations shown in Table 2 which were determined for estimating the concentrations of HMs and PAHs in urban stormwater, the risk assessment procedure was applied to estimate their risks to human health. The models for assessing the risk posed by HMs and PAHs in urban stormwater are represented by Eqs. (9) and (10), respectively.

$$
\begin{aligned}
\mathrm{HI}= & 0.05 \times \mathrm{Al}+68.20 \times \mathrm{Cr}+2.70 \times \mathrm{Mn}+0.02 \times \mathrm{Fe}+1.33 \times \mathrm{Ni} \\
& +0.63 \times \mathrm{Cu}+0.10 \times \mathrm{Zn}+409.18 \times \mathrm{Cd}+10.83 \times \mathrm{Pb}
\end{aligned}
$$

Where: The abbreviations of HMs are derived from Table 2.

$$
\begin{aligned}
\mathrm{ILCR}= & \frac{1.190789424}{243236} \times 0.001 \times \mathrm{NAP}+0.001 \times \mathrm{ACY}+0.001 \times \mathrm{ACE} \\
& +0.001 \times \mathrm{FLU}+0.001 \times \mathrm{PHE}+0.01 \times \mathrm{ANT}+0.001 \times \mathrm{FLA} \\
& +0.001 \times \mathrm{PYR}+0.1 \times \mathrm{B}[\mathrm{a}] \mathrm{A}+0.01 \times \mathrm{CHR}+0.1 \times \mathrm{B}[\mathrm{b}] \mathrm{F} \\
& +1 \times \mathrm{B}[\mathrm{a}] \mathrm{P}+0.1 \times \mathrm{IND}+5 \times \mathrm{D}[\mathrm{a}] \mathrm{A}+0.01 \times \mathrm{B}[\mathrm{g}] \mathrm{P}
\end{aligned}
$$

Where: The abbreviations for PAHs are given in Table 2.

\subsection{Risk map}

Risks posed by HMs and PAHs in urban stormwater generated from each grid cell $(1 \mathrm{~km} \times 1 \mathrm{~km})$ were calculated using Eqs. (9) and (10). The traffic and land use parameters adopted for risk assessment were identified as outlined in step (1). The risk map showing the risk posed by HMs and PAHs in urban stormwater from the study catchment is presented in Fig. 5. From the risk map, the critical areas generating stormwater with high risk to human health can be clearly identified. This provides guidance for the implementation of effective stormwater management strategies in the critical areas to mitigate the identified risk. 


\section{Results and discussion}

\subsection{Risk map}

As evident in Fig. 5, the red coloured grid cells represent the HI values greater than 1 and the ILCR values greater than $10^{-6}$. This indicates that the grid cells in red colour show that both, HMs and PAHs loads in urban stormwater generated from these areas can pose risks to human health. The grid cells with red colour are areas with numerous industrial and commercial activities. This implies that industrial and commercial activities may create high risks to human health due to HMs and PAHs contributed to urban stormwater.

The orange grid cells are the areas with HI values less than 1 while the ILCR values are in the range of $10^{-6}$ and $10^{-4}$. This means that only PAHs load in the stormwater from these areas may pose potential cancer risks to human health while HM loads in the stormwater does not pose risks. It is evident from Fig. 5, that the orange and red grid cells cover most of the urban areas in the selected catchment. Hence, in order to minimise the potential risk to a safe level, the stormwater generated from urban areas needs to undergo appropriate treatment for the removal of PAHs to safe levels. The green grid cells are where HI values are smaller than 1 and the ILCR values are less than $10^{-6}$, which means both, HMs and PAHs load in urban stormwater from these areas are not detrimental to human health. It is noteworthy that the condition of potential risk arising individually from HMs load with $\mathrm{HI}>1$ or PAHs load with ILCR $<10^{-4}$ was not found in the risk map derived (Fig. 5) for the study area. However, the risk map would be different for other areas where this risk assessment approach could be applied.

The identification of the priority areas having high risk arising from urban stormwater pollution can provide guidance for the strategic implementation of appropriate treatment measures. For example, Water Sensitive Urban Design (WSUD) has been widely applied to improve urban stormwater quality (Kuller et al., 2016). According to the risk map, it can be suggested that appropriate WSUD techniques need to be implemented in the critical areas in red colour rather than other areas, in order to remove HMs and PAHs in stormwater to minimise the risk to human health.

\subsection{Identification of the most toxic PAHs in urban stormwater}

The average risk from a single PAH in urban stormwater generated from all the grid cells in the catchment was determined. The toxicity of each PAH was derived by dividing the average risk posed by the single PAH with the risk posed by multiple PAHs in urban stormwater. The contribution to the risk from a single PAH is shown in Table 3. From Table 3, it is evident that the contribution of the risk from heavy molecular weight PAHs (PAHs with 5-6 benzene rings) is relatively much higher than in the case of light molecular weight PAHs (PAHs with 2-4 benzene rings). This indicates that heavy molecular weight PAHs are more carcinogenic to human health than the light molecular weight PAHs in urban stormwater. Therefore, it is recommended that controlling the generation of heavy PAHs can reduce the impacts of urban stormwater pollution to a safe level. For example, braking and starting activities are a primary source of PAHs due to inadequate combustion of gasoline (Gunawardena et al., 2012). Therefore, it is important to focus on the production of new types of fuels and lubricants with reduced concentrations of heavy PAHs.

\section{Conclusions}

This study developed a mathematical model to estimate catchment wide urban stormwater quality based on traffic and land use characteristics. Following on, a technically robust approach was developed based on the mathematical model to quantitatively estimate the risk posed by HMs and PAHs in urban stormwater generated from a catchment. This approach can be applied to identify the relatively highly polluted areas within a large catchment and provide recommendations for effective placement of stormwater treatment systems in these critical areas. In addition, heavy molecular weight PAHs in stormwater were identified as the most toxic PAH species to human health.

\section{Acknowledgements}

The authors would like to acknowledge the Chinese Scholarship Council (CSC) and Queensland University of Technology (QUT) for the scholarship provided to the first author for undertaking this doctoral study and Gold Coast City Council for providing baseline data.

\section{Appendix A. Supporting information}

Supplementary data associated with this article can be found in the online version at http://dx.doi.org/10.1016/j.ecoenv.2017.06.073.

\section{References}

APHA, 2004. Standard Methods for the Examination of Water and Wastewater. American Public Health Association, American Water Works Association, Water Environment Federation, Washington DC.

Birch, G.F., Matthai, C., Fazeli, M.S., Suh, J.Y., 2004. Efficiency of a constructed wetland in removing contaminants from stormwater. Wetlands 24 (2), 459-466.

Bozdogan, H., 1987. Model selection and Akaike's information criterion (AIC): the general theory and its analytical extensions. Psychometrika 52 (3), 345-370.

Chen, S.-C., Liao, C.-M., 2006. Health risk assessment on human exposed to environmental polycyclic aromatic hydrocarbons pollution sources. Sci. Total Environ. 366 (1), 112-123.

Chiew, F.H.S., Mudgway, L.B., McMahon, T.A., 1997. Urban stormwater pollution. Clayton, CRC Catchment Hydrol.

Cressie, N., 2015. Statistics for Spatial Data. John Wiley \& Sons.

Diggle, P., Ribeiro, P.J., 2007. Model-Based Geostatistics. Springer Science \& Business Media, New York.

Egodawatta, P., Goonetilleke, A., 2006. Characteristics of pollutants built-up on residential road surfaces. Proceedings of the 7th International Conference on HydroScience and Engineering, Philadelphia, U.S.A.

Egodawatta, P., Thomas, E., Goonetilleke, A., 2007. Mathematical interpretation of pollutant wash-off from urban road surfaces using simulated rainfall. Water Res. 41 (13), 3025-3031.

Egodawatta, P., Thomas, E., Goonetilleke, A., 2009. Understanding the physical processes of pollutant build-up and wash-off on roof surfaces. Sci. Total Environ. 407 (6), 1834-1841.

ESRI, 2016. "ArcGIS Help 10.4." Retrieved 09 May 2016, 2016, from 〈http://resources. arcgis.com/EN/HELP/MAIN/10.1/index.html\#//00qn0000013t000000〉.

Gunawardana, C., Goonetilleke, A., Egodawatta, P., Dawes, L., Kokot, S., 2011. Role of solids in heavy metals buildup on urban road surfaces. J. Environ. Eng. 138 (4), 490-498.

Gunawardana, C., Goonetilleke, A., Egodawatta, P., Dawes, L., Kokot, S., 2012. Source characterisation of road dust based on chemical and mineralogical composition. Chemosphere 87 (2), 163-170.

Gunawardana, C., Egodawatta, P., Goonetilleke, A., 2014. Role of particle size and composition in metal adsorption by solids deposited on urban road surfaces. Environ. Pollut. 184, 44-53.

Gunawardena, J., Egodawatta, P., Ayoko, G.A., Goonetilleke, A., 2012. Role of traffic in atmospheric accumulation of heavy metals and polycyclic aromatic hydrocarbons. Atmos. Environ. 54, 502-510.

Gunawardena, J., Ziyath, A.M., Egodawatta, P., Ayoko, G.A., Goonetilleke, A., 2014a. Influence of traffic characteristics on polycyclic aromatic hydrocarbon build-up on urban road surfaces. Int. J. Environ. Sci. Technol. 11 (8), 2329-2336.

Gunawardena, J., Ziyath, A.M., Egodawatta, P., Ayoko, G.A., Goonetilleke, A., 2014b. Mathematical relationships for metal build-up on urban road surfaces based on traffic and land use characteristics. Chemosphere 99, 267-271.

Herngren, L., Goonetilleke, A., Ayoko, G.A., 2005. Understanding heavy metal and suspended solids relationships in urban stormwater using simulated rainfall. J. Environ. Manag. 76 (2), 149-158.

Herngren, L.F., 2005. Build-up and Wash-off Process Kinetics of PAHs and Heavy Metals on Paved Surfaces Using Simulated Rainfall. Queensland University of Technology, Australia (PhD Degree).

IRIS, 2015. Tuesday, 17 March 2015. "A-Z List of Substances." Retrieved 02 April 2015, 2015, from 〈http://cfpub.epa.gov/ncea/iris/index.cfm?Fuseaction = iris. showSubstanceList\&list type $=$ alpha\&view $=\mathrm{I}\rangle$.

Jiang, Y., Hu, X., Yves, U.J., Zhan, H., Wu, Y., 2014. Status, source and health risk assessment of polycyclic aromatic hydrocarbons in street dust of an industrial city, NW China. Ecotoxicol. Environ. Saf. 106, 11-18.

Jyethi, D.S., Khillare, P., Sarkar, S., 2014. Risk assessment of inhalation exposure to polycyclic aromatic hydrocarbons in school children. Environ. Sci. Pollut. Res. 21 (1) 366-378.

Khillare, P., Hasan, A., Sarkar, S., 2014. Accumulation and risks of polycyclic aromatic 
hydrocarbons and trace metals in tropical urban soils. Environ. Monit. Assess. 186 (5), 2907-2923

Kuller, M., Bach, P., Ramirez-Lovering, D., Deletic, A., 2016. The location choice of water sensitive urban design within a city: a case study of Melbourne. IWA World Water Congr. Exhib.

Liu, A., Liu, L., Li, D., Guan, Y., 2015. Characterizing heavy metal build-up on urban road surfaces: implication for stormwater reuse. Sci. Total Environ. 515-516, 20-29.

Ma, Y., Egodawatta, P., McGree, J., Liu, A., Goonetilleke, A., 2016. Human health risk assessment of heavy metals in urban stormwater. Sci. Total Environ. 557-558, 764-772.

Ma, Y., Liu, A., Egodawatta, P., McGree, J., Goonetilleke, A., 2017a. Assessment and management of human health risk from toxic metals and polycyclic aromatic hydrocarbons in urban stormwater arising from anthropogenic activities and traffic congestion. Sci. Total Environ. 579, 202-211.

Ma, Y., Liu, A., Egodawatta, P., McGree, J., Goonetilleke, A., 2017b. Quantitative assessment of human health risk posed by polycyclic aromatic hydrocarbons in urban road dust. Sci. Total Environ. 575, 895-904.

Mummullage, S., Egodawatta, P., Ayoko, G.A., Goonetilleke, A., 2016. Use of physicochemical signatures to assess the sources of metals in urban road dust. Sci. Total Environ. 541, 1303-1309.

Nisbet, I.C., LaGoy, P.K., 1992. Toxic equivalency factors (TEFs) for polycyclic aromatic hydrocarbons (PAHs). Regul. Toxicol. Pharmacol. 16 (3), 290-300.

Novotny, V., Sung, H.M., Bannerman, R., Baum, K., 1985. Estimating nonpoint pollution from small urban watersheds. Water Pollut. Control Fed. 57 (4), 339-348.

Sartor, J.D., Boyd, G.B., Agardy, F.J., 1974. Water pollution aspects of street surface contaminants. Water Pollut. Control Fed. 46 (3), 458-467.

US EPA, 1984. Guidelines Establishing Test Procedures for the Analysis of Pollutants Under Clean Water Act: Method 610 - polynuclear aromatic hydrocarbons. 49. US Environmental Protection Agency, Washington, DC, pp. 43344-43352.

US EPA, 1989. Risk Assessment Guidance for Superfund, Volume I, Human Health Evaluation Manual (Part A). US Environmental Protection Agency, Washington, DC.

US EPA, 1994. Metod 200.8: Trace Elements in Waters and Wastes by Inductively Coupled Plasma-mass Spectrometry. US Environmental Protection Agency, Washington, DC.

US EPA, 1996. Pressurized Fluid Extraction (PFE). US Environmental Protection Agency, Washington, DC.

US EPA, 2005. Human Health Risk Assessment Protocol for Hazardous Waste Combustion Facilities. US Environmental Protection Agency, Washington, DC.

Wang, S., He, Q., Ai, H., Wang, Z., Zhang, Q., 2013. Pollutant concentrations and pollution loads in stormwater runoff from different land uses in Chongqing. J. Environ. Sci. 25 (3), 502-510.

Wold, S., 1978. Cross-validatory estimation of the number of components in factor and principal components models. Technometrics 20 (4), 397-405.

Zheng, N., Wang, Q., Zhang, X., Zheng, D., Zhang, Z., Zhang, S., 2007. Population health risk due to dietary intake of heavy metals in the industrial area of Huludao city, China. Sci. Total Environ. 387 (1), 96-104. 